\title{
Los dos tiempos del perdón en Vladimir Jankélévitch ${ }^{1}$
}

\section{Two instants for forgiveness in Vladimir Jankelevitch}

\author{
Senda Inés Sferco ${ }^{2}$ \\ Consejo Nacional de Investigaciones Científicas y Tecnológicas, CONICET \\ Universidad de Buenos Aires, Argentina
}

Recepción: 13 de septiembre del 2018

Evaluación: 26 de septiembre del 2018

Aceptación: 25 de octubre del 2018

\footnotetext{
1 Investigaciones en Filosofía política francesa contemporánea, Consejo Nacional de Investigaciones Científicas y Tecnológicas de Argentina.

2 Dra. Filosofía y Dra. Ciencias Sociales, Investigadora del CONICET, y del Instituto de Investigaciones Gino Germani de la Facultad de Ciencias Sociales de la Universidad de Buenos Aires, Argentina.

Correo electrónico: senda.sferco@gmail.com
}

Sferco, S. (2019). Los dos tiempos del perdón en Vladimir Jankélévitch. 


\title{
Resumen:
}

La perspectiva de Vladimir Jankélévitch ha abordado ampliamente el "perdón” como problema filosófico, ético-moral y político. Atento a los acontecimientos que marcaron a fuego el siglo $\mathrm{XX}$, sus reflexiones reescribirán tanto la vivencia de la Segunda guerra mundial, que lo proscribe profesionalmente y lo compromete en la Resistencia francesa, como la experiencia de formar parte de una sociedad que, años más tarde, abrirá el debate acerca de la "prescriptibilidad" de los crímenes contra la humanidad. La hipótesis que organiza este artículo es que habría dos momentos, dos tiempos del perdón en la perspectiva de este autor, que estarían atravesados por estas experiencias biográficas e históricas. Estos dos tiempos, no secuenciables, marcarían, de un modo más profundo e insondable, una tensión paradójica que atravesará el pensamiento de V. Jankélévitch: el perdón, verdadero y puro, puede ser concebido en el horizonte de una ética hiperbólica, pero, también es legítima la posibilidad de no perdonar como modalidad política de la justicia. De esta manera, enmarcando este estudio en una articulación entre filosofía y vida, exponemos una heurística profunda de distintas fuentes bibliográficas primarias y secundarias, a fin de reconocer los 'dos tiempos' en el modo de abordar la cuestión del perdón en la perspectiva jankélévitchiana.

Palabras clave: perdón, temporalidad, imprescriptibilidad, justicia, verdad, política

\begin{abstract}
:
The point of view of Vladimir Jankelevitch has broadly covered the "forgiveness" as a philosophical problem, an ethical, moral and political one. Regarding the events that marked with fire the XX century, his thoughts rewrote both the livelihood of the second world war, that proscribes him professionally and that binds him in the french resistance, as well as the experience of being part of a society that, some years later, opened the debate about "prescriptive" of crimes against humanity. The hypothesis that organizes this article is the idea of having two moments, two instants of forgiveness in the perspective of this author, that are pierced by these biographic and historic experiences. These two instants, not sequential ones, would mark, in a deep and fathomless way, a paradoxical tension that cross the thoughts of $\mathrm{V}$. Jankelevitch: the forgiveness, true and pure, can be conceived in the horizon of an hyperbolic ethic, but there is also a
\end{abstract}


legit possibility to not forgive as a kind of politics of justice. In this manner, framing this study in an articulation between philosophy and life, we show a deep heuristic from different primary and secondary bibliographic sources, in order to acknowledge the "two instants" in the way of approach the matter of forgiveness in the Jankelevitch perspective.

Keywords: forgiveness, temporality, imprescriptibility, justice, truth, politics

\section{Les deux temps du pardon chez Vladimir Jankélévitch}

\section{Résumé:}

Le point de vue de Vladimir Jankélévitch a largement abordé le "pardon" comme un problème philosophique, éthico-moral et politique. Attentif aux événements qui ont marqué violemment le XXe siècle, ses réflexions réécrivent à la fois l'expérience de la Seconde Guerre mondiale, qui l'a proscrit professionnellement et engagé dans la Résistance française, ainsi que l'expérience d'appartenance à une société qui, des années plus tard, ouvrira le débat sur la "prescriptibilité" des crimes contre l'humanité. L'hypothèse construite par cet article consiste en l'existence, d'après cet auteur, de deux moments, de deux temps du pardon, qui seraient traversés par ces expériences biographiques et historiques. Ces deux temps, non séquencés, marqueraient d'une manière plus profonde et insondable, une tension paradoxale qui traverse la pensée de V. Jankélévitch : le pardon, véritable et pur, peut être conçu à l'horizon d'une éthique hyperbolique ; mais, la possibilité de ne pas pardonner, comme modalité politique de la justice, est aussi légitime. De cette façon, en situant cette étude dans une articulation entre philosophie et vie, nous exposons une heuristique profonde de différentes sources bibliographiques primaires et secondaires, afin de reconnaître les "deux temps" dans la manière d'aborder la question du pardon dans la perspective jankélévitchienne.

Mots-clés: pardon, temporalité, imprescriptibilité, justice, vérité, politique

\section{Os dois tempos do perdão em Vladimir Jankélévitch}

\section{Resumo:}

A perspectiva de Vladimir Jankélévitch abordou amplamente o "perdão" como problema filosófico, ético-moral e político. Atento aos acontecimentos 
que marcaram o fogo no século $\mathrm{XX}$, suas reflexões reescrevem tanto a vivência na Segunda Guerra Mundial, que o proscreve profissionalmente e o compromete na Resistencia francesa, como a experiencia de formar parte da sociedade que, anos depois, abrirá o debate acerca da "prescriptibilidade" dos crimines contra a humanidade. A hipótese que organiza este artigo é que haveria dois momentos, dois tempos do perdão na perspectiva desse autor, que estariam atravessados pelas experiencias biográficas e históricas. Esses dois tempos, não sequenciáveis, marcariam, de um modo mais profundo e insondável, uma tensão paradoxal que atravessará o pensamento de $\mathrm{V}$ Jankélévitch: o perdão, verdadeiro e puro, pode ser concebido no horizonte de uma ética hiperbólica; mas também, é legitima a possibilidade de não perdoar como modalidade política da justiça. Desta maneira, marcando este estudo numa articulação entre filosofia e vida, exporemos uma heurística que afunda distintas fontes bibliográficas primarias e secundarias, a fim de reconhecer os "dois tempos" no modo de abordar a questão do perdão na perspectiva jankélévitchiana

Palavras-chave: perdão, temporalidade, imprescritibilidade, justiça, verdade, política 


\section{Introducción}

Las lecturas contemporáneas coinciden en demarcar dos momentos en la vida y en la obra de Vladimir Jankélévitch (Montmollin, 2000; Schwab, 2010; Hansel, 2012; Tonon, 2014). Uno, el de su época de juventud, donde la herencia bergsoniana imprime de cierto élan ${ }^{3}$ vital humanista sus escritos metafísicos. Otro, el que adviene marcado por la Segunda guerra mundial y por su compromiso activo en la Resistencia francesa, que teñirá de rigor moral su perspectiva vitalista. Uno y otro momento no representan, empero, compartimentos estancos. Al contrario, las inquietudes reflexivas de Jankélévitch suelen retomarse una y otra vez para ser repensadas, repotenciadas, reposicionadas, atravesando de modo diagonal, su pensamiento. Sin embargo, la experiencia de la guerra marca un antes y un después en su modo de relacionarse con el mundo que lo rodea (LiscianiPetrini, 2017, p. 40). La vivencia del horror y de la muerte, la asunción de su propia "judeidad" , la decepción frente a la hipocresía social, la reflexión acerca de la necesidad de actuar como llamado moral, etc., no sólo dejan su huella en la escritura, sino que afectan su toma de posición respecto de diversos temas, entre los que se encuentra la cuestión del perdón.

El estudio que presentamos a continuación se enmarca en las perspectivas que abordan los vínculos entre filosofía y vida, sobre la hipótesis de que existe una relación entre las tensiones socio-históricas vivenciadas en carne propia por el autor y los modos de elaboración del "perdón" como problema filosófico. Este enfoque heurístico requirió considerar tres niveles bibliográficos: 1) un corpus de material de archivos, registros epistolares y biográficos del autor; 2) los principales de los textos del autor sobre el tema; 3) lecturas secundarias de diversos especialistas contemporáneos sobre la obra del autor. Según este

3 Las traducciones del francés al español fueron realizadas por la doctora Dra. Martha Pardo Segura, las cuales están precedidas de la sigla N.d.T., y de [...] paréntesis cuadrados para palabras cortas dentro del texto, para palabras o títulos cortos de obras. N.d.T. ímpetu

4 Varios intérpretes de su obra coinciden en que éste es el momento en el que emerge "la judeidad" de Jankélévitch (Schwab, 2015, p. 260; Lisciani-Petrini, 2017, p. 40-41; Hansel, 2012 p. 25). Él mismo en su texto de 1957 « Le judaïsme, problème intérieur », [N.d.T. El judaísmo, problema interior] da cuenta de que "Il ne suffit pas pour cesser d'être juif de se convertir. Il ne suffit pas pour cesser d'être un juif russe, d'être naturalisé français. Le fait d'être juif est un fait qui ne s'efface ni par la naturalisation, ni par la conversion." (Schwab, 1984, p. 39).

N.d.T. "No es suficiente convertirse para dejar de ser judío. No es suficiente para cesar de ser un judío ruso de haberser naturalizado francés. El hecho de ser judío es un hecho que no se borra ni por naturalización ni por la conversión."

Sferco, S. (2019). Los dos tiempos del perdón en Vladimir Jankélévitch. 
recorrido teórico-metodológico, entonces, podemos adelantar que es posible configurar dos modos del "perdón" reflexionados por Vladimir Jankélévitch, según va siendo tramitada ética y políticamente la experiencia de la guerra. A continuación, presentaremos las similitudes y diferencias entre ambos momentos, considerando tanto sus aspectos filosófico-metafísicos como las paradojas que suscita, para el autor, su aplicación histórico-política.

\section{Una fractura biográfica}

Los archivos epistolares de Jankélévitch guardan una carta dirigida a quien fuera uno de sus principales maestros en la École Normal Supérieur ${ }^{5}$, Louis Beauduc, de fecha 30 de diciembre de 1941. Allí Jankélévitch relata: "La guerre a coupé ma vie en deux. Il ne me reste rien de mon existence avant 1940, pas un livre, pas une photo, pas une lettre."6 (Jankélévitch, 1979, en: Schwab, 1995, p. 274). Son los primeros días de Ocupación Alemana en Paris. Han allanado su departamento familiar de la rue de Rennes ${ }^{7}, y$, tal como cuenta, desolado: “...ils ont vidé par les pillards, avec toute ma bibliothèque musicale et la plupart de mes livres [...] Je n'ai donc plus un Discours de la méthode, ni un cahier de Chopin."8 (1995, p. 274). 010). h inactuel/actuel", 2013Paris: ad atravesada por diferentes ritmos y tensiones creadoras.

Vladimir Jankélévitch, que nació en Bourges en 1903 en el seno de una familia rusa-judía, había sido convocado por el ejército francés el año anterior, en 1939, para hacer frente a la avanzada alemana. Fue herido en la batalla de Mantes, en 1940, y debió pasar dos meses hospitalizado. Ese mismo año, luego de escribir la carta que citamos, Jankélévitch perdería su cargo de profesor en la universidad de Lille, ya que debido a la nacionalidad de sus padres ${ }^{9}$ no

\footnotetext{
N.d.T. Escuela Normal Superior de Louis Beauduc

6 N.d.T. "La guerra cortó mi vida en dos. No me queda nada de mi existencia antes de 1940, ni libro, ni foto, ni carta."

7 N.d.T. calle de Rennes

8 N.d.T. "vaciaron por saqueadores, con toda mi biblioteca de música y la mayoría de mis libros [...] Así que no tengo un Discurso del método, ni un cuaderno de Chopin."

9 El 20 de diciembre 1940, Jankélévitch escribe a Louis Beauduc dando cuenta de su angustia y de la absurda arbitrariedad de estas medidas : "On m'a découvert deux grands-parents impurs, car je suis, par ma mère, demi-juif; mais cette circonstance n'aurait pas suffi si je n'avais, de surcroît, été métèque par mon père. Cela faisait trop d'impuretés pour un seul homme." (Schwab, 1995, p. 265). N.d.T. "Me descubrieron dos abuelos impuros, pues yo soy, por mi madre, mitad-judío, pero esta circunstancia no habría bastado si yo no hubiera sido, además de eso, meteco [extranjero instalado en Francia] por mi padre. Eso hacía demasiadas impurezas para un solo hombre."
} 
podía ser considerado «francés de origen». Aun si, en razón de haber servido a la patria, por un breve lapso recuperará este puesto, tras la promulgación del Estatuto de los Judíos de Vichy en 1940, será completamente revocado de toda actividad de enseñanza. Así, «paria y proscripto» -al decir de la filósofa noruega Joelle Hansel (2012, p. 26)- se refugiará en Toulouse, y, junto a toda su familia entrará en la clandestinidad y tendrá parte activa en la Resistencia.

En la época de la Ocupación, Toulouse fue la "zona libre" de Francia. Al menos durante un buen tiempo. Allí, excluido de la Universidad, casi sin recursos, Jankélévitch dictó cursos particulares. Enseñó filosofía en distintos cafés encubiertos y realizó algunas publicaciones clandestinas gracias a sus jóvenes amigos de la Resistencia ${ }^{10}$. Acechado por constantes peligros, su doble "condición" de judío y resistente era muy difícill1 y se vio complicada todavía más luego de la entrada de la armada alemana en la zona libre. En otra carta también dirigida a su maestro y amigo Louis Beauduc, escrita el 30 diciembre de 1943, Jankélévitch expresaba su gran preocupación: "l'existence est devenue dangereuse, les nuits sont troublées et le lendemain est incertain." "I2 (Schwab, 1995, p. 295).

El 19 de agosto de 1944 Toulouse fue liberada. Jankélévitch estaba a salvo. Tal como expresará el autor años más tarde en el artículo "Pardonner?"'l3 (1971), el sentimiento de haber "sobrevivido por azar" no lo abandonará nunca. Febril, retorna a una escena filosófica francesa que antes lo había

10 Entre las que se cuentan los escritos Le malentendu [El malentendido] (1941), Du mensonge [De la mentira] (1942), Le nocturne [El nocturno] (1942), que serán publicados en 1942 por la editora Marius Audin de la ciudad Lyon, gracias a antiguos estudiantes suyos del Lycée du Parc de Lyon, donde Jankélévitch había dictado clases en el año 1933.

11 En una entrevista célebre publicada en l'Arc en 1979, Jankélévitch dejó plasmadas las contradicciones que implicaban de ahora en más vivir atravesado por el doble estatuto de «judío y resistente»: « Les juifs étant mis à l'écart dès le début, considérés comme des parias, n'avaient pas le choix. Il n'y avait pas pour eux matière à option... Mais d'un autre côté, la Résistance était pour eux encore plus difficile que pour d'autres. Le refus n'était donc pas le même pour les uns et pour les autres. Il était à la fois plus facile et plus difficile pour les uns et pour les autres. » (1979, p. 95) Cf. Testimonios compilados en Schwab, 2015, pp. 260-263.

N.d.T. "Los judios que estaban marginados desde el comienzo, considerados parias, no tenían elección., no habia opción para ellos ... Pero, por otro lado, la Resistencia era incluso más difícil para ellos que para otros. Por lo tanto, el rechazo no era el mismo para ambos. Era, a la vez, tan fácil y tan dificil para todos."

12 N.d.T. "La existencia se ha vuelto peligrosa, las noches son problemátcas y el mañana es incierto."

13 N.d.T. Perdonar (1971)

Sferco, S. (2019). Los dos tiempos del perdón en Vladimir Jankélévitch. 
valorado como una "joven promesa"14, pero ya nada es lo mismo, el contexto ha cambiado y él ya no "encaja". Si bien años más tarde, en 1951, será nombrado Profesor de la cátedra de Philosophie Morale ${ }^{15}$ en la Sorbona, y ello implica ciertamente una importante consagración de su carrera académica, no significa la inserción en su propio tiempo. Al contrario, nuestro autor manifestará varias veces (Jankélévitch y Berlowitz, 1987) la sensación de cierto andar díscolo en la escena filosófica francesa ${ }^{16}$, así como una suerte de "aislamiento" que, a veces hará pie en un tono crítico respecto de sus contemporáneos, otras, en cierta melancolía o en un lamento, al menos, extemporáneo ${ }^{17}$. Según confiesan sus propias palabras: "Maintenant il n' y a plus de place en France que pour les troupeaux: marxistes, catholiques,

${ }^{14}$ Henri Bergson, su maestro, había elogiado el primer artículo publicado en 1924 por Jankélévitch "Deux philosophies de la vie [Dos filosofías de la vida]: Bergson, Guyau" en la Revue philosophique de la France et de l'étranger, [N.d.T. Revista filosófica de Francia y del extranjero] en una carta dirigida a nuestro autor, escrita el 12 de mayo de 1924: "Ou je me trompe beaucoup, ou ce premier travail présage des oeuvres qui seront une importante contribution à la pensée philosophique." (Jankélévitch, 1994, p. 63).

N.d.T.“O me equivoco mucho o este primer trabajo presagia obras que serán una contribución importante para el pensamiento filosófico."

Años más tarde, en una carta del 10 de septiembre de 1939, cuando Jankélévitch será llamado al ejército, Bergson le escribirá: "Je fus jadis l'un des premiers, peut-être le premier, à vous prédire un bel avenir philosophique. Je ne m'étais pas trompé." (1994, pp. 97-98).

N.d.T. "Fui antaño uno de los primeros, quizás el primero, en predecirle un excelente futuro filosófico. No me había equivocado"

15 N.d.T. Filosofía moral

16 La filosofía francesa de la época había preferido, además, inclinarse hacia las reflexiones propias de la "metafísica alemana" y a la recepción de la perspectiva ontológica de Martin Heidegger, que será fuertemente deslegitimada por Jankélévitch.

17 Este caso, que aquí mencionamos solamente a manera de un ejemplo de distanciamiento, puede dar cuenta peculiarmente, a nuestro parecer, de cierto gesto reflexivo anacrónico, que en lugar de deslegitimarse a sí mismo en su desfasaje, intentará poner en valor el destiempo como gesto crítico-filosófico. Esta distancia marca en reiteradas oportunidades puntos de clivaje por él mismo reconocidos (Jankélévitch y Berlowitz, 1987, pp. 139-140). Recordemos que, frente a las grandes edificaciones de la filosofía de la historia de tinte humanista o marxista, Jankélévitch insistía en plantear un método de trabajo filosófico atento al tratamiento singular de las subjetividades con las que se forja una experiencia temporal que es siempre individual a la vez que compartida. Para ello, tomaba distancia de toda pretensión de registro unívoco de las cosas y ejercía una práctica de la intuición que permitiera sentirlas de otra manera y asirlas fragmentariamente en su diferencia específica. No serán categorías absolutas las que en consecuencia rijan la arquitectura de su pensamiento; al contrario, su perspectiva se armará de nociones semi-gnósticas, productoras de saberes siempre "a medias" - el "Je-ne-sais-quoi" [No sé qué] y el "Presque rien"[Casi nada] (Jankélévitch, 1954), por nombrar tan solo algunas de ellas-, capaces de tematizar la dinámica surgiente de la realidad y de pautar, también, el pulso de elaboración de sus ideas. 
existentialistes. Et je ne suis d'aucune paroisse."18 (1995, p. 230). No sólo su modo de reflexión filosófica y moral resulta distante de las discusiones "de paroisse" [de parroquia] que interesan a su presente filosófico, sino que la experiencia de la guerra recientemente vivida y su rol activo en la Resistencia, también lo diferencian de quienes se han quedado a pensar alrededor de la Sorbona. Sentencioso, no le alcanzan las palabras de desprecio para criticar, por ejemplo, al existencialismo sartreano por su falta de compromiso efectivo durante la Ocupación. Para él, los seguidores de Sartre, no son sino meros "neo-resistentes del café de Flore", que, en lugar de comprometerse en cuerpo y alma, "se comprometieron a comprometer"que no es sino la del reclamo permanente de ificando la importancia el perdu vida que represen"”, ${ }^{19}$. Si bien este punto refiere a un descrédito militante de Jankélévitch para con Sartre, es preciso recordar que también se impone entre ambos una distancia teórica, puesto que para el filósofo del Existencialismo el pensamiento 'intuitivo' y 'optimista' bergsoniano resultaba por lo menos "ingenuo" para asir la "angustia" que la postguerra había puesto en el centro de la cuestión existencialista. Pero Jankélévitch ya había producido un desplazamiento en este punto, cuando en su libro dedicado a "Bergson" publicado en 1931 se propuso ir "más allá' de su maestro sumando "inefabilidad" y "negatividad" (Worms, 2009, p. 398) al planteo de la temporalidad creadora. Si, tal como nos legaba la lección bergsoniana el tiempo es el vector de una realidad siempre surgiente, algo puede todavía volver a nacer en cada momento (Bergson, 1989) pero también algo en su retrospección queda indefectiblemente atrás. Así, al movimiento creador y libre del élan, [ímpetu] frívolamente mal entendido como "optimista" por ciertas perspectivas existencialistas, Jankélévitch impone gravedad e irreversibilidad, alegando por un mandato de prudencia que se pruebe cada vez capaz de calibrar la "justa medida" del acto libre y creador de este élan [ímpetu] (1989 p. 200). En este sentido, luego de la guerra, la defensa del élan [ímpetu] vital en Jankélévitch implicará la reafirmación de un impulso de vida que ya nunca más podrá ser tematizado como un movimiento hacia delante meramente innovador y optimista. Según su perspectiva, el tiempo comporta tanto una capacidad intrínseca de inicios como un carácter "irreversible" 20 que lo anclará sin retorno en determinados

18 N.d.T. "Ahora, no hay sitio en Francia sino para los rebaños: marxistas, católicos, existencialistas. Y yo no soy de ninguna parroquia"

$19 C f$. V. Jankélévitch, en Schwab, 2015, p. 65.

20 Si bien la idea de "irreversibilidad" es temprana en su escritura y ya la hallamos en su Philosophie Première (1954) N.d.T. Primera Filosofía, Jankélévitch le dedica un desarrollo específico en la obra que lleva como título L'irréversible et la nostalgie, de 1974. N.d.T. Lo irreversible y la nostalgia

Sferco, S. (2019). Los dos tiempos del perdón en Vladimir Jankélévitch. 
actos históricos. La experiencia de la guerra, así, parte aguas también respecto de su conceptualización de la temporalidad, puesto que, a sus ojos, los sucesos acontecidos no tienen posible vuelta atrás y exigen categorías específicas capaces de dar cuenta de su peso. Como podemos intuir, consecuentemente, la conceptualización del "perdón" se verá atravesada por este doble carácter temporal: a la vez que emergerá como instante oportuno para una creación generosa e inédita, devendrá también una instancia de cristalización histórica "contra" el tiempo, puesto que hay actos que no pueden ser perdonados.

\section{El perdón como clave para una ética hiperbólica}

En sintonía con la herencia bergsoniana y con la impronta moral que caracteriza de ahora en más su escritura, Jankélévitch se abocará inmediatamente después de la guerra a la redacción de una extensa trilogía, intitulada Tratado de las virtudes, publicada en 1949. Allí, actualizando la tradicional analítica aristotélica, el autor sitúa el perdón al lado de virtudes cardinales como la caridad, el don y el amor.

En el tomo I del Tratado, subtitulado "Le sérieux de l'intention" 21 , el perdón toma parte de la problemática causal y emotiva que se extiende alrededor de la consideración moral de las "intenciones" de los actos. ¿Cuáles fueron los motivos que impulsaron a efectuar el acto ocurrido y cuáles serían los eventuales motivos para poder perdonarlo?, es la pregunta que va marcando el hilo de la argumentación (Jankélévitch, 1983, p. 25-29). Retomando el concepto bergsoniano de órgano-obstáculo ${ }^{22}$, el autor plantea que, a nivel lógico, la acción efectuada pervive como impedimento en el perdón,

21 N.d.T. Lo serio de la intención.

22 En La evolución creadora (1907), Bergson había advertido que toda percepción es posible gracias a la activación de un órgano que la efectúa, en un campo de percepción específico y delimitado, generando una representación finita de cosas finitas (por eso no es representable ni verificable el infinito ni el absoluto). Un límite viene dado por la peculiar percepción para la cual está preparado cada órgano, al igual que el ojo en su radio de visión, el órgano nos permite percibir, experimentar y conocer dentro de determinado campo, a la vez que nos impide, percibir, experimentar y conocer más allá de esos límites. Tal como lo recuerda Trejos Marín, “...es justamente gracias a esta delimitación que el conocimiento se hace posible. El obstáculo que nos impide ir más allá es precisamente, y por eso mismo, el órgano que nos permite conocer" (1993, p. 79). En este sentido, ninguna percepción podría ser total. Todo acto perceptivo, al contrario, es parcial y contingente, parte de un movimiento temporal siempre haciéndose. Jankélévitch, sintetizará la apuesta de su maestro, mediante la expresión "La matière est l'organe-obstacle de la durée spirituelle" N.d.T. "La materia es el órgano-obstáculo de la duración espiritual" (1959, p. 168), aludiendo a una realidad atravesada por diferentes ritmos y tensiones creadoras. 
imponiendo un movimiento a contratiempo atento a pensar la paradoja que, frente al acto, implicaría perdonar lo ocurrido. El filósofo hace pie en esta tensión que formula como "a pesar de" -"malgré"-, puesto que si asumimos que la dinámica tensional es constitutiva de los actos humanos, si no hubiese habido "faute" -falta, culpa-, no habría en consecuencia nada que perdonar. La falta es así la razón de ser del perdón por el hecho mismo que es su obstáculo, por eso "Le rapport du pardon à la faute est donc à la fois causal et "concessif”"23 (Jankélévitch, 1983, p. 27). Si el órgano-obstáculo es móvil y aquiescencia, " "Malgré" est la spécialité même du pardon (...) Le pardon pardonne à la fois bien-que et parce-que, et en même temps il ne pardonne ni parce-que ni bien-que; et d'autre part ces deux vérités (l'un et l'autre, $n i$ l'un ni l'autre) sont à la fois vraies et fausses.... Et ainsi à l'infini. $»^{24}(1983$, p. 27). En consecuencia, identificar un obstáculo, dar cuenta de dónde radica la tensión del "a pesar de", exige elaborar una torsión subjetiva; es decir, crear y efectuar un gesto generoso que se pruebe capaz de escindir el perdón del cálculo lógico de sus razones, de la cuenta de sus motivos, para situarlo en cambio en los gradientes de una relativización virtuosa.

Asimismo, en la misma línea que busca desactivar el quid pro quo que da lugar a cadenas de reciprocidades propias de los mecanismos vengativos, en este primer texto el perdón aparece como una pieza fundamental para instaurar la dinámica del "mérito" 25 . Es necesario, en este sentido, entender que la idea de "mérito", para este autor, no es piramidal, sino que al contrario, emerge para poner en consideración el punto de partida de cada historia singular, su propia razón: "ce qu'il a dû faire pour le faire"[N.d.T. aquello que se ha debido hacer para hacerlo”] (Jankélévitch, 1983, p. 25). Su mirada legitima así el recorrido personal, experiencial y subjetivo, como registro decisivo a fin de componer las tensiones que llevaron al hecho. El perdón, así, aparece

23 N.d.T. "La relación del perdón con la falta es por tanto a la vez causal y concesivo"

24 N.d.T. “' A pesar de” es la especialidad del perdón (...) El perdón perdona aunque y porque, y al mismo tiempo, no perdona ni porque ni aunque; $y$, por otro lado, estas dos verdades (tanto la una como la otra y ninguna de ellas) son tanto verdaderas como falsas. Y asi hasta el infinito. "

25 "Le mérite fait donc acception du contexte économique et social ; mais il tient compte aussi des fatalités éthologiques et biologiques, de l'hérédité, de la maladie, du "hándicap" au départ; il tient compte de l'obstacle et de toutes les circonstances qui constituent le "donné"." (Jankélévitch, 1983, p. 26)

N.d.T. "Luego, el mérito tiene sentido con el contexto económico y social; pero también tiene en cuenta al comienzo las fatalidades etológicas y biológicas, la herencia, la enfermedad, la incapacidad; tiene en cuenta el obstáculo y todas las circunstancias que constituyen lo "dado"

Sferco, S. (2019). Los dos tiempos del perdón en Vladimir Jankélévitch. 
como un acto siempre meritorio, en un vínculo que requiere primeramente un "don de tiempo"26. El perdón emerge como un gesto de caridad que no debe apresurarse. Ha de proponerse, al contrario, esperar antes de ejercer un juicio, tomarse el tiempo para re-sentir las singularidades implicadas. Esta atención a una dimensión modal, cualificable y subjetiva de la temporalidad, exige pensar al perdón más allá de la definición de su "quid" (puesto que su sustrato ontológico ya no sería unívoco), en la dinámica del "quod" con el cual va habilitando temporalmente su consideración efectiva a través de los obstáculos que ha de atravesar para cumplirse. Se abre entonces al análisis un espectro de gradaciones, que ha de aportar datos acerca del "cómo", de la "manera", del "itinerario" (1983, p. 26) que van sufriendo estas distintas experiencias subjetivas tematizadas por el perdón. Únicamente a través del recorrido específico de estas trayectorias singulares podría erigirse el perdón como reclamo. Allí radica su mérito. Sólo así podría tener lugar y tiempo la excedencia agraciada ${ }^{27}$ por la cual y a pesar de, determinado acto pudiera ser perdonado.

Más adelante, en el tomo II de este mismo Tratado, intitulado "Les vertus et l'amour"28, Jankélévitch profundizará la relación entre el perdón y las virtudes,entre el perdón y las virtudesrio, emerge para poner en del eomentos de su vida que represens, situando su articulación en el centro de la reflexión alrededor de la "gracia amorosa", para dar cuenta de un desplazamiento: el perdón aparece como una donación que permite el pasaje de "la gratitud a la gratuidad" (1986, p. 245). Según su análisis, si la gratitud todavía opera dentro de una lógica del intercambio recíproco que tiene a la caridad en el otro polo, el perdón, en cambio, habrá de exigir la gratuidad del don gracioso. Es decir, de "ce don qui n'est ni prêt, ni vente, ni location, et qui n'est jamais rémunéré, et qui ne suppose ni contracts ni actes notariés, ce don, n'est-ce pas reproduit tous les mystères de l'acte créateur?, et ceci alors même qu'il n'édifie, en apparence, aucune œuvre positive et visible." 29

26 Ya veremos años más tarde como Jacques Derrida profundizará el exámen de las paradojas de esta condición en su obra Donner le temps, N.d.T. Dar (el) tiempo, de 1991.

27 El autor todavía no refiere al "don gracioso", como planteamos seguidamente, recién en el tomo siguiente de la Trilogía el perdón es comprendido como "don gratuito".

28 N.d.T. Las virtudes y el amor.

29 N.d.T. "Este don que no es ni préstamo, ni venta, ni alquiler, que nunca se paga, y que no supone contratos ni actos notariales, ¿cierto que este don reproduce todos los misterios del acto creativo? $Y$ esto, incluso que no construye, aparentemente, ninguna obra positiva y visible." 
(Jankélévitch, 1986, p. 260). El autor se sustentará en los textos del Evangelio y de la palabra de los Apóstoles, para ilustrar las paradojas constituyentes de esta Gracia: amar a quienes nos odian, bendecir a quienes nos maldicen, rezar por sus perseguidores ${ }^{30}$. En efecto, en la dinámica del pecado y de la indulgencia se tensaría una dinámica paradojal que, en nombre de la piedad, permite desactivar la violencia. Sacrificio y heroísmo, entonces, se hallan en la base del acto de perdonar, que consuma en su don gratuito algo de sublime y de misterioso. Pero este pasaje no ocurre por mera emanación; cierta "transmutación ascensional" ha de ocurrir a nivel subjetivo para que esta donación efectivamente desborde toda selectividad y acontezca como "gracia" (Jankélévitch, 1986, pp. 256-257). Es necesario "devenir amor", producir la excedencia que permita pasar al acto: "Aimer, donner, pardonner, créer, -ces quatre mots désignent quatre formes d'initiative, quatre formes d'innocence: sous ces quatre formes la conscience accomplit un mouvement efférent et direct vers l'autre ou vers l'objet, un mouvement sans retour sur soi." 31 (1986, p. 267).

El movimiento hacia el otro propio del perdón, finalmente, trata de un acto siempre singular y relacional. Implica, cada vez, una iniciativa que excede el sujeto autónomo. Para ello, el perdón debe ser primeramente "pedido". Sólo así se activa el movimiento, que, va de suyo, comienza cuando el agresor solicita al agredido que éste efectúe una acción, una donación, una gracia, un acontecimiento gratuito y sin razón para con él, que implique perdonarlo. El agredido, por su parte, puede decidir o no cumplimentar su pedido. Desde Jankélévitch, de un modo ciertamente interesante, el perdón no puede ser universal ni tampoco justificable, sino que es siempre un acto de pedido específico. Lisciani-Petrini (2017, p. 48) y Hansel subrayan la doble herencia, cristiana y judía de Jankélévitch, que se haría presente en este punto: "Le Pardon manifeste la tensión entre l'être juif de Jankélévitch et sa proximité toute spirituelle avec le christianisme." ${ }_{22}$ (Hansel, 2012, p. 135). En efecto, al inscribir el perdón gracioso en un gesto sublime y heroico al servicio de una ética hiperbólica, el autor permanece ligado a los ideales de la teología

30 Mateo, V, 43-44; Lucas, VI, 27-28; Romanos, XII, 14; I Corintios, IV, 12.

31 N.d.T. "Amar, dar, perdonar, crear, estas cuatro palabras designan cuatro formas de iniciativa, cuatro formas de inocencia: bajo estas cuatro formas la conciencia realiza un movimiento eferente y directo hacia el otro o hacia el objeto, un movimiento sin un retorno sobre uno mismo “

32 N.d.T. "El Perdón manifiesta la tensión entre el ser judío de Jankélévitch y su proximidad muy espiritual con el cristianismo." 
cristiana. Sin embargo, en paralelo, al reconocer un tiempo específico para la instancia de su "solicitud", remite a la condición ética del judaísmo que concibe al perdón como parte de una relación en la que habrá de ser primeramente pedido por el agresor, y a su vez, el agredido tendrá la posibilidad -nunca la obligación- de concederlo ${ }^{33}$. En este sentido, la experiencia del perdón para Jankélévitch comienza en el momento preciso en que el agresor puede comenzar a pedirlo, aunque este inicio no garantiza que consiga su propósito. Así, el arco virtuoso del perdón se extiende sobre los modos de calibrar esta experiencia tensional y ambivalente; por su parte, la temporalidad del acto mismo de perdonar no será extensiva y tendrá tan solo la consistencia de gracia de un instante.

\section{El perdón verdadero y el instante temporal}

Las ideas tempranas desarrolladas en Le Traité des Vertus (1949) ${ }^{34}$ respecto del perdón -trasmutación amorosa, singularidad meritoria, don gratuito, pedido, movimiento hacia el otro-, serán consumadas en el libro que dedicará especialmente a este tema, Le Pardon, ${ }^{35}$ publicado en 1967. En estas páginas, Jankélévitch se propone presentar un estudio puramente filosófico de esta cuestión, una caracterización rigurosamente sistemática de la dinámica virtuosa que daría lugar a un "verdadero perdón” o un "perdón puro" (1967, p. 7). Para ello, definirá tres rasgos que son condición necesaria para su conceptualización: su vinculación al otro, su gratuidad -retomando las tesis antes expuestas-, y su instantánea temporalidad.

En lo que sigue desarrollaremos brevemente la peculiar temporalidad que supone el "perdón verdadero" jankélévitchiano.

33 Es interesante el comentario efectuado por Hansel (2012:135), subrayando uno de los tantos intercambios entre el pensamiento de Jankélévitch y Lévinas, quién, en ocasión del coloquio en el que Jankélévitch presenta el problema del perdón, Lévinas da una clase sobre el tratado talmúdico Yoma, donde se enumeran las condiciones para la expiación de faltas en el día de Kippur : «Les fautes de l'homme envers Dieu sont pardonnées par le Jour du Pardon; les fautes de l'homme envers autrui ne lui sont pas pardonnées par le Jour du Pardon, à moins que, au préalable, il n'ait apaisé autrui. » (Hansel, 2012, p. 135). N.d.T. "Las faltas del hombre hacia Dios son perdonadas por el Día del Perdón; las faltas del hombre hacia el prójimo no le son perdonadas por el Día del Perdón, a menos que, con antelación, él no haya apaciguado al semejante"

34 N.d.T. El tratado de las virtudes (1949)

35 N.d.T. El Perdón. 
Dijimos, la experiencia del perdón comienza cuando puede ser "pedido". Sin embargo, independientemente del modo temporal que este acto comporta a nivel subjetivo, no es sino en un instante fútil y azaroso que se impone el perdón como acto. La exposición jankélevitchiana es categórica al plantear que el perdón no puede instalarse en una temporalidad que no sea instantánea, puesto que no puede aspirar a un miramiento retrospectivo ni futurológico que recapitule argumentativamente o razonablemente la consideración de sus actos. El perdón, aquí, sólo puede hacer uso del flujo del tiempo a fin de dar inicio instantáneamente a la creación inédita de su "don gracioso". Su modalidad es sin razones; su tiempo un "Casi-nada" - Presque-rien- (Cf. Jankélévitch, 1954, p. 71; 1980, p. 7), que escapa a toda conceptualización secuenciada. En consecuencia, el autor se empeñará en diferenciarlo de otras pseudo formas del perdón, que, a su parecer, buscan 'justificar' causalmente su ocurrencia, como si de algún modo buscasen sostener a través de los plazos de una duración temporal el don que no pueden efectuar como gracia e instante.

La primera forma que el autor diferencia del perdón es la práctica de usura temporal o la consideración del tiempo como medicina doloris. Frente a la recurrente creencia de nuestra doxa, insiste en interrogar: ¿Es cierto que el tiempo cicatriza las heridas y que entonces es posible perdonar? ¿Habría una correlación entre sufrimiento y crimen que pueda ser atenuada de un modo equiparable a lo largo del tiempo? (Cf. Jankélévitch, 1967, p. 57). Su respuesta es negativa; desde su mirada, el crimen no solo causa dolor, sino que es, ante todo, una falta moral, una agresión al otro y una ruptura de la comunidad de prójimos. Delegarle el perdón al tiempo es una forma de pseudo perdón -señala (1967, p. 58)-, en la que el tiempo especula con el olvido ‘caricaturizando' el otorgamiento de un perdón como gracia mediante una supresión de la memoria del pasado.

La segunda forma costumbrista es la "excusa", que tampoco debe confundirse con el perdón, ya que solo comporta una mera intelección. En tanto tal, la excusa, a diferencia del aplazo temporal, no precisa del tiempo para jugar con el olvido, sino que se plantea como una actividad personal e intelectual mediante la cual el perdón simula una identificación con la comprensión. Falsa copia, secundidad, para este autor la excusa no cuenta con ninguno de los tres requisitos del perdón verdadero: no es un acontecimiento instantáneo, ni se vincula en tiempo presente con el otro, ni tampoco es un don gratuito (1967, p. 84). Ya en el tomo II del Tratado de las Virtudes, Jankélévitch subrayaba: 
"C'est l'excuse qui a besoin de raisons pour acquitter le coupable: car l'excuse, excusant la faute par les circonstances atténuantes, ou constatant que la faute est nulle et inadvenue, l'excuse est conservatrice et nivelante. Le pardon, lui, pardonne justement parce que la faute est inexcusable." ${ }^{\prime 36}$ (1986, p. 267). La excusa reduce los actos del otro a un sistema causal cuyo secuenciamiento se expone luego a la manera de una "comprensión". De acuerdo a la exigencia jankélévitchiana, la afirmación "comprender es perdonar" solo tiene veracidad en cuanto advenga ligada al momento preciso en el cual, por un acto sentido, valiente y agraciado, el perdón tiene ocurrencia como acto. Únicamente en ese instante, el perdón es como el amor; puede efectuarse sin límites y darse sin razones, completamente.

La tercera forma de pseudo perdón que identifica Jankélévitch es la del perdón estratégico. A diferencia de las dos anteriores, es la más "astuta", aunque también por eso mismo la menos laudable de aspiración virtuosa. Quien "perdona estratégicamente" medita, sopesa, confía y 'corre el riesgo' de absolver al acusado, advierte. El perdón, de esta manera, se transforma en un objeto de cálculo hacia el futuro. Se dispone así a ingresar en una especulación de expectativas, a la apuesta de “...que l'avenir justifiera sa confiance, que son calcul s'avérera exact." ${ }^{37}$ (1967, p. 142). No es por tanto un perdón puro, ya que opera con condiciones, extendido temporalmente y su cuenta anula toda gratuidad.

Estas diferencias permiten a Jankélévitch definir conceptualmente el espaciotiempo del "perdón puro", que se ratifica instantáneo, relacional y gratuito, situando su ámbito de operatividad en una dimensión total, sin razón y sin condición. El "perdón verdadero", entonces, se dispone como pieza clave de la Tarea -con mayúsculas- de una "ética hiperbólica", que aspira a movilizar y actualizar aquello que lo humano tiene de "más virtuoso", por sobre las consideraciones y cálculos de sus razones particulares. En efecto, si "L'éthique n'est pas un accord parfait majeur sans histoire, mais la solution sans cesse recommencée d'une alternative sans cesse renaissante,

\footnotetext{
36 N.d.T. "Es la excusa que necesita razones para absolver al culpable: pues la excusa, perdonando la falta por las circunstancias atenuantes o constatando que la falla es nula e inadvertida, la excusa es conservadora y nivelante. El perdón, él, perdona justamente porque la falta es inexcusable"

37 N.d.T. “... que el futuro justificará su confianza, que su cálculo resultará correcto.”
} 
-l'alternative déchirante de la culture individuelle et du dévouement social." "38 (Jankélévitch, 1986, p. 254), el perdón aparece como la posibilidad siempre latente de un recomienzo, como la reactualización de un acto que, en cada circunstancia, pueda incrustar una "alternativa" agraciada y verdadera para el bien común. La fuerza del perdón verdadero proviene entonces de esta ligazón al horizonte de una ética hiperbólica; allí radica su potencia que trasciende toda cuenta de las partes y permite bifurcar toda deliberación dada por razonable, en nombre del bien común. Ya veremos, en lo que sigue, las consecuencias ético-políticas de esta postura. En todo caso, la elaboración de una conceptualización « verdadera » del perdón, ratifica que, "plus encore que le don, le pardon manifeste la gratuité de l'instant charitable, car il exprime l'independence de notre choix par rapport à toute raison de choisir, et rend ainsi plus évident le caractère artificiel, mesquin et dérisoire des motivations rétrospectives." ${ }^{39}$ (1986, p. 267).

El horizonte virtuoso del perdón queda así consumado en su definición. Sin embargo, aun si el "perdón verdadero" aquí se erige desde una pureza instantánea contra la "mezquindad retrospectiva" de los "artificiales e irrisorios motivos de la temporalidad", veremos que las taxativas calificaciones de Jankélévitch no eximen la tematización del órgano-obstáculo situado como tensión en el centro mismo de su propia escritura: frente a los crímenes del nazismo el autor no puede convalidar perdón posible. Se confiesa incapaz de su don y de su gracia. No habría ética hiperbólica plausible de proyectar en un horizonte humanitario y virtuoso tanto monstruoso desgarro. No perdonar, recordemos, también es una de las opciones responsivas frente a la solicitud de ser perdonado.

\footnotetext{
38 N.d.T. "La ética no es un gran acuerdo perfecto sin historia, sino la solución siempre cambiante de una alternativa siempre renovadora: la alternativa desgarradora de la cultura individual y la abnegación social"

39 N.d.T. "aún más que el don, el perdón manifiesta la gratuidad del instante caritativo, pues expresa la independencia de nuestra escogencia con relación a toda razón de seleccionar, y vuelve más evidente el carácter artificial, mesquino y irrisorio de las motivaciones restrospectivas."
} 


\title{
Lo imprescriptible
}

\author{
"Notre époque a le cœur bien léger: \\ elle aurait désormais le droit de l'avoir léger. \\ elle aurait le cœur juridiquement léger." \\ (Jankélévitch, 1986a, p. 48). \\ "Nuestra era se siente muy tranquila: \\ ella tendría en adelante el derecho de estar serena: \\ ella estaría legalmente reposada. (N.d.T.)
}

En efecto, el 3 de enero de 1965, un par de años antes de la aparición de Le Pardon" ${ }^{40}$ en la sección de "Opinions libres"41 del diario Le Monde, Jankélévitch había publicado una carta condenando la intención del Estado francés de "perdonar" los crímenes contra la humanidad. La "excusa" sobre la que se fundamentaba la consideración estatal aludía, tal como Jankélévitch había advertido en su definición conceptual, a la "suficiencia" de un lapso temporal: transcurridos ya veinte años de la perpetración de los crímenes se planteaba la posible "prescripción" de estos actos. Haciendo frente a esta factibilidad, en febrero de ese mismo año Jankélévitch también escribe un artículo en la Révue administrative ${ }^{42}$ que lleva por título "L'imprescriptible".43 (1965) -"lo imprescriptible"-. Este texto, donde retoma argumentos ya trabajados en 1956 (y que versionaría nuevamente en 1971), tiene como eje argumentativo dar una respuesta a la pregunta "Pardonner?"4". A partir de estas distintas intervenciones Jankélévitch se pronuncia públicamente contra la voluntad de legalizar el olvido, asumiendo implicancias jurídicas, sociales y políticas que dan cuenta de la activa responsabilidad de Jankélévitch como intelectual de su tiempo ( $C f$. Le Guyader, 2010). También estas posturas, ciertamente interesantes para el análisis que nos ocupa, darán testimonio de las diversas tensiones que enfrenta el autor a la hora de tratar de hacer congeniar sus formulaciones teóricas y las posibilidades prácticas de su perspectiva filosófica. Jankélévitch, en este sentido, siempre se caracterizó por sostener una escritura sincera, que sigue el hilo de su pensamiento y que no esquiva las ambivalencias humanas. Así se expresa a la hora de dar cuenta

\footnotetext{
40 N.d.T. El Perdón.

41 N.d.T. Opiniones libres.

42 N.d.T. Revista administrativa.

43 N.d.T. El imprescriptible.

${ }^{44}$ N.d.T. ¿Perdonar?
} 
del desplazamiento de posición que este hecho en él suscita, compartiéndonos cierto "torcimiento subjetivo" que se asume como testimonio de esta experiencia "imprescriptible":

Dans une étude purement philosophique sur Le Pardon, que nous avons publiée par ailleurs, la réponse à la question Faut-il pardonner? semble contredire celle qui est donnée ici. Il existe entre l'absolu de la loi d'amour et l'absolu de la liberté méchante une déchirure qui ne peut être entièrement décousue. Nous n'avons pas cherché à réconcilier l'irrationalité du mal avec la toute-puissance de l'amour. L'amour est fort comme le mal, mais le mal est fort comme le pardon. ${ }^{45}$ (Jankélévitch, 1986a, p. 15)

Si tomamos sus propias palabras, cuando no solo el amor, sino también el mal es tan fuerte como el perdón ${ }^{46}$, toda esperanza de superación dialéctica queda desalentada. El acto acontecido, sin más, se impone a la totalidad únicamente como órgano-obstáculo. No hay manera de traspasar lo ocurrido. No hay modo de producir su negación y superarlo. Los crímenes contra la humanidad son actos cuya magnitud de horror no permite el acompasamiento de sus hechos al contratiempo del "a pesar de" del órgano-obstáculo, no puede habilitar un tratamiento paradojal de los hechos históricos que entrama. Jankélévitch es enfático al respecto: estos actos no pueden ser perdonados y serán siempre un obstáculo.

Aún si hemos subrayado la relación entre la experiencia de la guerra y la producción filosófica alrededor del perdón de parte del autor, marcando dos tiempos en su obra, es necesario no confundir este corrimiento problemático con una interpretación simplista que los sitúe a la manera de 'dos momentos contradictorios $^{97}$ en la filosofía de Jankélévitch. En este sentido, antes que

45 N.d.T."En un estudio puramente filosófico de El Perdón, que hemos publicado en otra parte, la respuesta a la pregunta ¿Es necesario perdonar?, parece contradecir la dada aquí. Existe entre el absoluto de la ley del amor y el absoluto de la libertad maliciosa un profundo dolor que no puede ser totalmente inconexo. No hemos tratado de reconciliar la irracionalidad del mal con la omnipotencia del amor. El amor es fuerte como el mal, pero el mal es fuerte como el perdón.” (Jankélévitch, 1986a, p. 15)

46 El autor insiste en que moralmente los hombres tienen la misma capacidad de amor y de mal: "l'amour est plus fort que le mal, et le mal est plus fort que l'amour, ils sont plus fort l'un que l'autre." (1967, p. 213).

47 Cf. Tillette (2007) que, frente a la pretensión de delimitar un período "filosófico" y otro "militante" en la escritura del autor, insiste en un vínculo indisoluble entre compromiso y filosofía en la obra de V. Jankélévitch, que se consuma en su experiencia testimonial. 
una contradicción lógica al interior de su obra, habría, a nuestro parecer, más bien un desplazamiento de foco problemático: no sólo esta cuestión ya estaba manifiestamente expuesta tanto en relación a la posibilidad siempre abierta de no perdonar, sino que ya había sido plasmada tempranamente en 1967, en su "Introduction au thème du pardon" [Introducción al tema del perdón], al referir a la magnitud inconmensurable del "mal" perpetrado por los nazis en la Segunda Guerra Mundial. Aquí Jankélévitch había calificado estos actos como "... un crime sans nom, un crime qui dépasse l'imagination" ${ }^{48}$ (1967, p. 257). Sin nombre ni número ni imaginación posible, los crímenes contra la humanidad no cumplen los requisitos que nuestro autor había sistematizado como legítimos para un "perdón verdadero". De hecho, el autor arguye que son "crímenes internacionales" que no involucraron sólo un acto particular o a una única persona sino a "la humanidad" toda entera. Asimismo, la crueldad de lo ocurrido da cuenta de una "inhumanidad" imposible de ser asimilada al sujeto autónomo y libre de derecho propio de la herencia ilustrada ${ }^{49}$ (Jankélévitch insiste varias veces sobre este punto: son "...des crimes contre l'essence humaine ou, si l'on préfère, contre "l'hominité" de l'homme en général." ${ }^{50}$ (1986a, p. 22). Tampoco sus criminales buscaron inscribirse en el campo de una ética jurídica puesto que no han pedido perdón, en consecuencia, no dieron inicio al proceso relacional e intersubjetivo por medio del cual podrían ser eventualmente perdonados (1986a, p. 22) $)^{51}$. De

48 N.d.T. “... un crimen sin nombre, un crimen que sobrepasa la imaginación” (1967, p. 257).

49 Más adelante, en el mismo texto, describirá la idea de "hominidad" ligada a su filosofía de la "ipseidad", explicando que “...le raciste visait bien l'ipséité de l'être, c'est-à-dire l'humain de tout homme. L'antisémitisme est une grave offense à l'homme en général. Les Juifs étaient persécutés parce que c'étaient eux, et non point en raison de leurs opinions ou de leur foi: c'est l'existence elle-même qui leur était refusée; on ne leur reprochait pas de professer ceci ou cela, on leur reprochait d'être. (...) Un Juif n'a pas le droit d' être; son péché est d'exister. (...) Mais le Juif n'est pas pour l'Allemand un simple "instrument de travail", il est en outre lui-même la matière première." (Jankélévitch, 1986a, pp. 22-25).

N.d.T. “ “.. el racista apuntaba más a la ipseidad del ser, es decir a lo humano de todo hombre. El antisemitismo es una grave ofensa para el hombre en general. Los judíos eran perseguidos porque eran ellos, y no por motivo de sus opiniones o de su fé: es la existencia misma que les es rechazada; no se les reprochaba profesar esto o aquello, se les reprochaba ser. (...) Un judío no tiene el derecho de ser; su pecado es existir. (...) Pero el judío no es para el alemán un simple "instrumento de trabajo", es además de el mismo, la materia prima."

50 N.d.T. "crímenes contra la esencia humana o, si se prefiere, contra la hominidad del hombre en general." (1986a, p. 22).

51 Desde la lectura de Jankélévitch, de un modo ciertamente polémico, "lo imperdonable" será extensible a Alemania toda entera. En Pardonner? [Perdonar?] dirige una acusación hacia todo el pueblo alemán, aludiendo a su reactualizada indiferencia frente a las atrocidades nazis que produjeron 
esta manera, “...tous les critères juridiques habituellement applicables aux crimes de droit commun en matière de prescription sont ici déjoués. "52 (1986a, p. 21). Tan "imperdonable" la dimensión del horror, como "imprescriptible" su temporalidad. En efecto, si la magnitud del mal, el volumen genocida de la Shoah, es tan inconmensurable que no podría aspirar a una gracia y resulta, entonces "imperdonable", la dimensión "imprescriptible", por su parte, se halla vinculada a los problemas de la temporalidad que edifican la éticamoral de Jankélévitch. Tal como hemos visto, en este punto la temporalidad no puede ser analizada como un flujo, tampoco puede ser conceptualizada como "excusa" o "estrategia" (las dos formas del pseudo perdón) puesto que el tiempo no es un factor plausible de erosionar lo acontecido y/o de especular con el olvido. Al contrario, la categorización "imprescriptible", tal como examinamos, refuerza la definición del acto como obstáculo: viene a subrayar la importancia de un hecho que ninguna temporalidad puede suspender; cristaliza su consistencia, y, lejos de atenuarse, multiplica su plena presencia en el tiempo. Es portador de un mal que nunca termina de pasar - al igual que en la rememoración brechtiana. De esta manera, a partir de lo imprescriptible, el acto -de un modo ciertamente problemático para un pensador de la temporalidad- ya no participa del tiempo.

Esta constatación de un límite frente a una exigencia de inconmensurabilidad virtuosa, como veremos, no sólo plantea un problema filosófico, sino que tiene consecuencias morales, jurídicas y políticas. En efecto, Jankélévitch comienza su opúsculo Pardonner? [¿Perdonar?], con la siguiente pregunta: "Est-il temps de pardonner, ou tout au moins d'oublier?" [iEs tiempo de perdonar o al

el exterminio de la mayoría de los Judíos de Europa y de otras personas en los campos de concentración: (Cf. 1986a, p. 49). Tampoco Alemania podría inscribirse en la relación vinculante requerida por su ética hiperbólica, puesto que los alemanes no han pedido perdón $(C f .1986$, p. 50). Ni asunción de culpabilidad por parte de los criminales, ni reflexión o debate social impulsado por los intelectuales. Con el desprecio por Alemania, Jankélévitch apunta explícitamente a Heidegger y los heideggereanos -olvidándose también que inmediatamente luego de la guerra, Karl Jaspers había dictado una serie de cursos sobre La cuestión de la culpabilidad que fueron publicados en 1946, donde distinguía cuatro nociones de culpa: criminal, moral, metafísica y política, ésta justamente la de la carga colectiva que debían asumir todos los alemanes luego de lo sucedido. Como sea, según su experiencia “...les intellectuels et moralistes allemands n'ont rien à dire. Cela ne les regarde pas." [N.d.T-...los intelectuales y moralistas alemanes no tiene nada que decir. Eso no les concierne.”] (1986a, p. 52). Jankélévitch dejará de escribir y hablar en alemán, y nunca más pondrá un pie en Alemania.

52 N.d.T. “...todos los criterios jurídicos habitualmente aplicables a los crímenes de derecho común en materia de prescripción aquí se impiden.” 
menos de olvidar?] (1986a, p.17). La expresión “ya es tiempo", que polemiza con el cálculo del Estado, plantea considerar un lapso temporal que reclama haber probado "suficiencia" en el presente. Recordemos que Jankélévitch había anulado la correspondencia entre perdón y "memoria doloris"; no puede por tanto convalidar dicha conciliación: ¿han sido necesarios veinte años para tomar dimensión de la brutalidad acontecida? ¿o para permitir que su horror gigantesco se disipe? Desde su visión, “...le temps qui favorise le pardon et l'oubli, le temps qui console, le temps liquidateur et cicatriseur n'atténue en rien la colossale hécatombe : au contraire il ne cesse d'en aviver l'horreur." (Jankélévitch, 1986a, p.26). Plantear una política de la prescriptibilidad, una práctica del olvido, deviene así una estrategia de complicidad con el genocidio, ya que es imposible "nihiliser le fait d'avoir fait" [nihilizar el hecho de haber hecho”] (Jankélévitch, 1967, p. 58). Jankélévitch brinda numerosos argumentos de ello, utilizando incluso la retórica fina que caracterizan sus disquisiciones, como las que en las páginas de este libro hace emerger eruditamente a través de las cacofonías del lenguaje, para distinguir la posible atenuación de los "efectos" -les effets- de los actos criminales, del imposible borramiento de los "hechos" - les faits: "Avec le temps, tout ce qui a été fait peut être défait, tout ce qui a été défait peut être refait, mais le fait-d'avoir-fait (fecisse) est indéfaisable." ${ }^{54}$ (1967, p. 62).

Podríamos, incluso, ir más allá y dar cuenta del rigor del aparato lógico del autor, para el cual, stricto sensu, ningún hecho se anularía en tanto tal y toda falta sería imprescriptible, siendo que rige una dinámica irreversible. Ciertamente hay aquí un halo metafísico que busca imponerse por una vía moral y virtuosa sobre las enmarañadas relaciones de fuerza de la materialidad de la historia. Pero este "afuera del tiempo" de la dinámica entre lo imperdonable y lo imprescriptible, es, también, una enorme potencia, puesto que su fuerza «...n'est pas soumise à la juridiction du droit et de la politique; au contraire, elle les contrôle en les empêchant de dériver vers un formalisme abstrait ou de porter atteinte aux personnes. La législation doit entériner ce qui est juste d'un point de vue moral. Le fait que les crimes nazis soient impardonnables les rend ipso facto imprescriptibles ${ }^{55}$ (Hansel, 2012, p.135).

\footnotetext{
53 N.d.T. “...el tiempo que favorece el perdón y el olvido, el tiempo que consuela, el tiempo liquidador y cicatrizador no atenúa en nada la colosal hecatombe: al contrario él no para de avivar el horror."

54 N.d.T. "Con el tiempo, todo lo que se ha hecho puede ser deshecho, todo lo que se ha deshecho puede ser rehecho, pero el hecho-de haber-hecho (hecho) no se deshace.

${ }^{55}$ N.d.T. «...no está sometida a la jurisdicción del derecho y de la política; al contrario, ella los controla impidiéndoles desviar hacia un formalismo abstracto o de atentar contra las personas. La
} 
De esta manera, aun cuando un Estado pueda intentar proclamar la prescriptibilidad de los crímenes, invocando una economía temporal por la cual al cabo de cierto tiempo estos crímenes ya no se aleguen punibles, habría una imprescriptibilidad a nivel de los hechos, que, a pesar de toda fuerza de ley, no podría borrarse. El perdón aparece entonces finalmente puesto a servicio de una construcción ética que precisa de la justicia para reactualizar cada vez la visión de sus obstáculos. Probablemente sea ésta la mejor lección jankélévitcheana. Si hacemos memoria, en el Tratado de las virtudes él ya trazaba una diferencia entre justicia, caridad y perdón, capaz de echar luz sobre esta articulación valorativa y política: la justicia, era una virtud compensatoria que operaba un cálculo siempre mensurable en la lógica del "donnant-donnant" [toma y daca/intercambio], mientras que la caridad y el perdón implicaban un don de gracia; por eso, estos últimos intervenían generosamente cuando los tribunales y los jueces no llegaban a completar su trabajo y pervivía entonces una demanda de justicia (Lisciani-Petrini, 2013, p. 90). Si es cierto que el perdón ha de actuar articulado a la justicia para pactar una y otra vez los acuerdos ético-sociales, no perdonar es entonces también el gesto que reposiciona en el centro de las tensiones sociales y políticas el órgano-obstáculo del acto acontecido, para recordar y exigir más justicia a la justicia, para reclamarle la continuidad de su trabajo. El perdón, como figura de una ética hiperbólica no podría entonces "rebajarse" a la altura de los tiempos prescriptibles de la escena pública, sino que debe imponer en ella una temporalidad otra, irreversible, que impulse el trabajo aun sin completar de la justicia. Por eso: "pardonner, ici, ne serait pas renoncer à ces droits, mais trahir le droit. Celui qui "garde rancune" aux criminels d'un tel crime en a donc littéralement le droit." ${ }_{66}$ (Jankélévitch, 1967, p. 68). Las palabras de Jankélévitch son decisivas y aún más sincero su autootorgamiento del "derecho a guardar rencor" del que varios autores (Tonon, 2014; Kemp 2010; Hansel, 2012) han remarcado su presencia. Ciertamente, aun si frente a la virtud, el resentimiento opera como traba u ofensa a un principio de caridad y de perdón, también, de un modo más "político", es un sentimiento que al rechazarlo -actúa-como derecho a un reclamo permanente de justicia (Kemp 2010). Jankélévitch mismo da cuenta del doble uso que

legislación debe ratificar lo que es justo desde el punto moral. El hecho que los crímenes nazis sean impedonables los convierte ipso facto imprescindibles."

${ }^{56}$ N.d.T. "perdonar, aquí, no sería renunciar a esos derechos, sino traicionar al drecho. El que "guarda rencor" a los criminales de tal crimen, tienen literalmente el derecho a hacerlo." 
permite este "re-sentir" empeñado contra todo paso del tiempo: "Quand la rancune est une simple hargne et une obstination toute négative, le pardon est un devoir de charité; mais quand la soi-disant "rancune" est en réalité une fidélité inébranlable aux valeurs et aux martyrs, c'est le pardon qui est une trahison." ${ }^{57}$ (1967, p. 73).

Fidelidad a los que han sufrido, derecho al rencor, es como si el tiempo imprescriptible plantease a la tarea política la impotencia de su hacer y la importancia de seguir sintiendo, puesto que frente al órgano-obstáculo acontecido, “...il reste une seule ressource: se souvenir, se recueillir. Là où on ne peut rien "faire", on peut du moins ressentir, inépuisablement." 58 (1986a, p. 62).

Para finalizar, y ratificando la relevancia reflexiva y política del vínculo entre filosofía y experiencia de vida, es necesario saber que las reflexiones de Jankélévitch lograron influenciar el debate público francés y la categoría de "imprescriptible" fue utilizada para dar fuerza de ley al voto del Parlamento contra la prescripción de los crímenes contra la humanidad ${ }^{59}$. La experiencia de la guerra vivida por el autor deja así una huella imborrable en su pensamiento y, probablemente sea ésta la apuesta más "política" de su perspectiva filosófica: el perdón, tomado por el horizonte virtuoso de una ética hiperbólica que le exige "verdad" y por la temporalidad imprescriptible que le impide olvidar, opera incrustando una fuerza en la arena pública ${ }^{60}$, que no es sino la del reclamo permanente de justicia.

57 N.d.T."Cuando el rencor es una simple hosquedad y una obstinación muy negativa, el perdón es un deber de caridad; pero cuando el supuesto "rencor" es, en realidad, una fidelidad inquebrantable a los valores y a los mártires, es el perdón el que es una traición.” (1967, p. 73).

58 N.d.T. "queda un único recurso: recordar, reflexionar. Ahí donde no se puede "hacer" nada, se puede al menos sentir, incansablemente." (1986a, p. 62).

59 Cf. Danlos, 2010.

${ }_{60}$ Peter Kemp, por su parte, parece intuir esta constatación: "Jankélévitch avait raison d'affirmer que tout ce qui est fait à moi-même est en principe pardonnable et que pour le pardon pur l'impardonnable n'existe pas dans ce rapport personnel. Par contre sur le plan politique et collectif, il y a des actes qui sont impardonnables, mais c'est parce que en dernière analyse le pardon pur n'a pas de sens en politique." (2010, p. 230)

N.d.T. “Jankélévitch tenía razón en afirmar que todo lo que es hecho por mí mismo es en principio perdonable y que por el perdón puro lo imperdonable no existe en ese vínculo personal. Por el contrario sobre el plan político y colectivo, hay actos que son imperdonables, pero es porque en el análisis final el perdón puro no tiene sentido en política." 


\section{Referencias}

Bergson, H. ([1907] 2007). L'évolution créatrice. Paris: Quadrige PUF.

Bergson, H. ([1896] 1969). La Pensée et le mouvant. Paris: PUF.

Danlos, J. (2010). De l'idée de crimes contre l'humanité en droit international. Caen: Publications Philosophie de l'Université de Caen.

Derrida, J. (1991). Donner le temps. 1. La fausse monnaie. Paris: Galilée.

Hansel, J. (2006). Lévinas. De l'Être à l'Autre._Paris: PUF.

Hansel, J. (2012). Jankélévitch. Une philosophie du charme. Paris: Manucius.

Jankélévitch (1924). Deux philosophies de la vie: Bergson, Guyau. Révue philosophique de la France et de l'étranger, (2) 49, pp. 402-449.

Jankélévitch, V. ([1931]1959). Henri Bergson. Paris: Félix Alcan.

Jankélévitch, V. (1948). Dans l'honneur et la dignité. Les Temps modernes, n.33., pp. 22-49.

Jankélévitch, V. ([1949] 1983). Traité des vertus. Le sérieux de l'intention. Tome I. Paris: Flammarion.

Jankélévitch, V. ([1949] 1986). Traité des vertus. Les vertus et l'amour. Tome II. Paris: Flammarion.

Jankélévitch,V. ([1953] 1954). Philosophie première. Introduction à une philosophie du "Presque". Paris: PUF.

Jankélévitch, V. (1956). L'austérité et la vie morale. Paris: Flammarion.

Jankélévitch, V. ([1957] 1980). Le Je-ne-sais-quoi et le Presque-rien. Tome I: La manière et l'occasion. Paris: Du Seuil.

Jankélévitch, V. (1967). Le Pardon. Paris: Aubier-Montaigne.

Jankélévitch, V. (1974). L’irréversible et la nostalgie. Paris: Flammarion.

Jankélévitch, V. (1979). Entretien. L'Arc. Num. 75, Paris.

Jankélévitch, V. (1986ª). L'impresciptible. Pardonner? Dans l'honneur et la dignité. Paris: Seuil.

Jankélévitch, V. et Berlowitz, B. (1978). Quelque part dans l'inachevé. Paris: Gallimard. 
Jankélévitch, V. et Schwab, F. (Ed). (1984). Sources. Paris: Seuil.

Jankélévitch, V. et Schwab, F. (Ed). (1994). Premières et dernières pages. Paris: Seuil.

Kemp, P. (2010). Le Pardon. F. Schwab, S. E. Bouratsis et J. M. Brohm (Comp.) Présence de Vladimir Jankélévitch. Le Charme et l'Occasion. pp. 221-231. Paris: Beauchesne. Le Guyader, A. Ambivalence du droit et paradoxe des Droits de l'Homme selon Jankélévitch. F. Schwab, S. E. Bouratsis et J. M. Brohm (Comp.) Présence de Vladimir Jankélévitch. Le Charme et l'Occasion. pp. 231-263. Paris: Beauchesne

Montmollin, I. (2000). La philosophie de Vladimir Jankélévitch. Paris: PUF.

Lisciani-Petrini, E. (2010). Jankélévitch inactuel/actuel. F. Schwab, S. E. Bouratsis et J. M. Brohm (Comp.) Présence de Vladimir Jankélévitch. Le Charme et l'Occasion. 175-191. Paris: Beauchesne.

Lisciani-Petrini, E. (2013). Charis. Essai sur Jankélévitch. Paris: Vrin.

Lisciani-Petrini, E. (2017). Le philosophe combattant : éthique et politique chez Jankélévitch. Révue Cités, Jankélévitch morale et politique, 70, PUF, Paris, 40-52.

Schwab, F. (Ed.) (1995). Correspondance. Une vie en toutes lettres. Lettres à Louis Beauduc (1923-1980). Paris: Liana Lévi.

Schwab, F. (Ed.). (2010). Présence de Vladimir Jankélévitch. Le Charme et l'Occasion. Paris: Beauchesne.

Schwab, F. (2011). Levinas et Jankélévitch, professeurs de dénuement. R. Burggraeve, J. Hansel, M.-A. Lescourret, J.-F. Rey et J.-M. Salanskis (Comp.). Lévinas autrement. Louvain: Peeters.

Schwab, F. (Ed.). (2015). V. Jankélévitch, L’Esprit de résistance. Textes inédits 1943 1983. Paris: Albin Michel.

Tillette, X. (2007). Emmanuel Levinas: les problèmes de la subjectivité, J. Hansel (Ed.). Levinas à Jerusalem. Paris: Klincksieck.

Trejos Marín, S. (2002). El imperativo moral en la filosofía de Vladimir Jankélévitch. Revista Filosofía Univ. de Costa Rica, XL (102), dic. 2002, pp. 139-145.

Worms, F. (2009). La philosophie en France au XXe siècle. Moments. Paris: Gallimard. 